\title{
Ocorrência de anticorpos anti-Neospora caninum em pequenas propriedades leiteiras do Uruguai
}

\author{
Occurrence of anti-Neospora caninum antibodies in small dairy farms in Uruguay
}

\section{Agustín Furtado $^{\mathrm{I}}$ Diego Rosadilla ${ }^{\mathrm{I}}$ Milton Cattáneo ${ }^{\mathrm{II}}$ Julián Bermúdez $^{\mathrm{II}}$ Rodrigo Puentes $^{*}$}

\section{- NOTA -}

\section{RESUMO}

\begin{abstract}
Neosporose é uma doença de distribuição mundial causada por um protozoário (Apicomplexa, Sarcocystidae), denominado Neospora caninum (N. caninum). Na América Latina, o protozoário foi diagnosticado no Uruguai, Brasil, Argentina, Chile, Paraguai e Peru. No Uruguai a prevalência em rebanhos leiteiros não foi determinada, havendo somente levantamentos sorológicos de algumas regiões do país em propriedades rurais de médio e grande porte. $O$ objetivo deste trabalho foi determinar a presença de animais sorologicamente positivos contra $N$. caninum em bacias leiteiras de pequenas propriedades com baixos recursos socioeconômicos da zona central do Uruguai (Estados de Durazno e Tacuarembó). Utilizando um Kit de ELISA comercial, foram analisados 734 soros provenientes de vacas leiteiras adultas, obtendo-se 211 positivos $(28,8 \%), 517$ negativos $(70,5 \%)$ e seis animais com resultado não determinado $(0,7 \%)$. Nossos resultados demonstram a exposição destes rebanhos ao parasito, sendo este o primeiro inquérito sorológico de $\mathbf{N}$. caninum em bacias leiteiras de pequenas propriedades no Uruguai.
\end{abstract}

Palavras-chave: Neospora caninum, ELISA, vacas em lactação, Uruguai.

\section{ABSTRACT}

Neosporosis is a worldwide disease caused by a protozoan (Apicomplexa, Sarcocystidae), called Neospora caninum (N. caninum). In Latin America was diagnosed in Uruguay, Brazil, Argentina, Chile, Paraguay and Peru. In Uruguay, the prevalence in dairy cattle is undetermined, with only a few reports in some areas from medium and large farmers. The main of this study was to determine the presence of serologically positive animals against $\mathbf{N}$. caninum in small dairy farmers in critical context from central region of Uruguay (Departments of Durazno and Tacuarembó). Using a commercial ELISA kit, 734 sera of adult dairy cows were analyzed, resulting in 211 positive (28.8\%), 517 negative (70.5\%) and six animals with uncertain outcome $(0.7 \%)$. The results demonstrated the exposure of cattle to the parasite, which is the first serological survey of $\mathbf{N}$. caninum in basins of small dairy farmers in critical context in Uruguay.

Key words: Neospora caninum, ELISA, dairy cows, Uruguay.

A Neosporose é uma doença de distribuição mundial causada pelo Neospora caninum ( $N$. caninum), um protozoário (Apicomplexa, Sarcocystidae) que atinge diversas espécies de mamíferos, sendo o cão o hospedeiro definitivo (MACALLISTER et al., 1998). A doença já foi descrita em diversos países da America Latina, como Uruguai, Brasil, Argentina, Chile, Paraguai e Peru (MOORE, 2005). No Uruguai a primeira vez que se demonstrou a presença de anticorpos em animais contra o parasito foi no ano de 1997, sendo logo confirmada em cães e vacas (BARBER et al., 1997; BAÑALES et al., 1998, 2000). No ano de 2006, um levantamento sorológico realizado em nível nacional, em rebanho de corte, encontrou uma prevalência de $13,25 \%$, com $73,8 \%$ das propriedades positivas (BAÑALES et al., 2006). Em

'Área de Inmunología, Departamento de Ciencias Microbiológicas, Universidad de la República Oriental del Uruguay, Las Places, 1550, CP11600, Montevideo, Uruguay. E-mail:rpuentes@ adinet.com.uy. *Autor para correspondência

"Área de Bacteriología, Departamento de Ciencias Microbiológicas, Universidad de la República Oriental del Uruguay, Montevideo, Uruguay 
contrapartida, estudos de prevalência em rebanhos leiteiros ainda são insuficientes, sendo apenas realizados estudos sorológicos no sul do país, onde se concentra a maior quantidade de propriedades leiteiras do Uruguai. A prevalência encontrada em propriedades leiteiras de médio porte (mais de 30 vacas em lactação) foi de $17 \%, 20 \%$ e $24 \%$ para os estados de Colônia, Florida e San José, respectivamente (PIAGGIO, 2006). A importância da infecção por $N$. caninum em propriedades com rebanhos leiteiros soropositivos é que há queda da produção de leite na primolactação (THUMOND \& HIETALA, 1997) e também perdas produzidas por reabsorções embrionárias, mumificações fetais, fetos autolisados, abortos e natimortos (CERNICCHIARO et al., 1998). O objetivo deste trabalho foi determinar a presença de animais soropositivos a $N$. caninum em bacias de pequenas propriedades leiteiras (com menos de 30 animais em lactação e com baixos recursos socioeconômicos) da região central do país (Estados de Durazno e Tacuarembó). Este tipo de propriedade é muito comum no Uruguai, o que determina um manejo muitas vezes desfavorável para uma produção de leite de qualidade.

Para o presente estudo, de 39 propriedades leiteiras, foram obtidas 734 amostras de soro de vacas em ordenha (416 provenientes de Durazno, 318 de Tacuarembó). As amostras foram obtidas por meio da coleta do sangue da veia caudal com seringas estéreis, sem anticoagulante, mantidas refrigeradas por 24 horas, quando o soro foi extraído por centrifugação a 3000rpm. Todas as amostras foram submetidas ao diagnóstico sorológico através de um kit de ELISA comercial (IDEXX ${ }^{\circledast}$, Liebefeld-Bern - Suiza), seguindo as recomendações do fabricante. Em paralelo, foi realizada uma enquete sobre a presença de outras espécies de animais nas propriedades estudadas.

Do total de amostras analisadas, 211 foram positivas $(28,8 \%), 517$ negativas $(70,5 \%)$ e 6 foram consideradas não determinadas $(0,7 \%)$. No Estado de Durazno, 105 amostras $(25,2 \%)$ foram positivas, 308 negativas (74\%) e 3 não determinadas $(0,72 \%)$ e, no de Tacuarembó, 106 foram positivas (33,3\%), 209 negativas $(65,7 \%)$ e 3 não determinadas $(0,94 \%)$.

Na região alvo do estudo, a baixa produção de leite tem sido verificada com frequência (dados não apresentados), inclusive tem sido observada a ocorrência de problemas reprodutivos, com casos de abortamento, no entanto sem confirmação laboratorial. Entre os anos 1999e 2000, N. caninum foi diagnosticado como causa de abortamento em $37 \%$ dos fetos bovinos enviados ao laboratório oficial de referência do Ministério de Ganadería, Agricultura y Pesca (MGAP) (BAÑALES et al., 2006), ressaltando os resultados do presente estudo, que relata até aproximadamente 30\% dos animais sororreatores para $N$. caninum. É importante destacar que, em 38 das 39 propriedades estudadas, constatou-se a presença de 2 ou mais cães em contato com as vacas, o que pode ser a fonte de contágio e disseminação do parasito, visto que o cão é um dos hospedeiros definitivos de $N$. caninum, e que estes animais poderiam se infectar a partir da ingestão de fetos e placentas contaminadas (McALLISTER et al., 1998; LINDSAY et al., 1999). Também neste tipo de produção, na época de escassez de alimentos (principalmente em secas importantes ou no inverno), é comum a alimentação dos animais fora das propriedades (nas estradas, com vizinhos), o que poderia influenciar a transmissão do parasito a outras propriedades.

Os resultados do presente estudo relatam, pela primeira vez, a presença de anticorpos anti- $N$. caninum em vacas de pequenas propriedades leiteiras na região central do Uruguai e fazem um alerta sobre a possibilidade de que estes estejam participando na manutenção do parasito nos rebanhos leiteiros do Uruguai.

\section{AGRADECIMENTO}

Ao laticínio "Nutrísima S.R.L”, ao Dr. José Queirolo, à Intendência Municipal de Durazno e aos produtores leiteiros dos Estados de Tacuarembó e Durazno por colaborarem com este projeto.

\section{REFERÊNCIAS}

BAÑALES P. et al. Aborto bovino por Neospora caninum en el Uruguay: primeros diagnósticos. Veterinaria, v.34, p.139140: 28-32, 1998.

BAÑALES P. et al. Bovine abortion in Uruguay caused by Neospora caninum: first diagnosis. CONGRESO MUNDIAL DE BUIATRÍA, 21., Punta del Este, Uruguay, 2000. Punta Del Este: Congresos \& Reuniones, 2000. V.1, p.41. Disponível em: <http://www.come.to/buiatrics2000>. Online. Acesso em: 10 nov. 2010.

BAÑALES, P. et al. A nationwide survey on seroprevalence of Neospora caninum in beef cattle in Uruguay. Veterinary Parasitology, v.139, p.15-20, 2006. Disponível em: <http:// www.ncbi.nlm.nih.gov/pubmed/16621288>. Acesso em: 15 fev. 2011. doi: $10.1016 /$ j.vetpar.2006.03.004.

BARBER J.S. et al. Prevalence of antibodies to Neospora caninum in differents canid populations. Journal Parasitology, v.83, n.6, p.1056 1058. 1997. Disponível em: <http://www.ncbi.nlm.nih.gov/pubmed/9406778>. Acesso em: 15 fev. 2011.

CERNICCHIARO, N. et al. Neosporosis: una enfermedad reproductiva a tener en cuenta. Veterinaria, v.34, p.33-42, 1998. 
DUBEY, J.P. Recent advances in Neospora and neosporosis. Veterinary Parasitology, v.84, p.349-367, 1999. Disponível em: <http://www.ncbi.nlm.nih.gov/pubmed/10456423>. Acesso em: 15 fev. 2011. doi: 10.1016/S0304-4017(99)00044-8).

LINDSAY, D.S. et al. Confirmation that the dog is a definitive host for Neospora caninum. Veterinary Parasitology, v.82, p.327-333, 1999. Disponível em: <http://www.ncbi.nlm.nih.gov/ pubmed/10384909>. Acesso em: 10 nov. 2010. doi: 10.1016/ S0304-4017(99)00054-0).

MCALLISTER, M.M. et al. Dogs are definitive hosts of Neospora caninum. International Journal of Parasitology, v.28, p.14731478, 1998. Disponível em: <http://www.ncbi.nlm.nih.gov/ pubmed/9770635>. Acesso em: 14 nov. 2011. doi: 10.1016/ S0020-7519(98)00138-6.
MOORE, D. P. Neosporosis in South America. Veterinary Parasitology, v.127, p.87-97, 2005. Disponível em: <http:// www.ncbi.nlm.nih.gov/pubmed/15631900>. Acesso em: 14 nov. 2010. doi: 10.1016/j.vetpar.2004.10.001.

PIAGGIO, J. Estudio transversal de neosporosis en la principal cuenca lechera del Uruguay. 2006. p.47. Tesis (Maestría) Programa de posgrado en Salud Animal, Facultad de Veterinaria Uruguay. Disponível em: <http://www.fvet.edu.uy/fvbiblio/archivos/ maestria.html>. Online. Acesso em: 15 fev. 2011

THUMOND, M.C.; HIETALA, S.K. Effect of Neospora caninum infection on milk production in first -lactation dairy cows. Journal of the American Veterinary Medical Association, v.210, p.672-674, 1997. Disponível em: <http://www.ncbi.nlm.nih.gov/ pubmed/9054999>. Acesso em: 15 fev. 2011. 